\title{
Mortality rates from cryptogenic fibrosing alveolitis in seven countries
}

\author{
Richard Hubbard, Ian Johnston, David B Coultas, John Britton
}

\begin{abstract}
Background - Registered mortality from cryptogenic fibrosing alveolitis (CFA) in England and Wales has increased substantially since the specific International Classification of Diseases code for CFA was introduced in 1979. However, since a significant proportion of deaths from CFA are misclassified as post inflammatory fibrosis (PIF), it is possible that the observed rise in CFA mortality is due to diagnostic transfer from this code. To investigate this, and to assess mortality trends in other countries, annual CFA and PIF mortality data from England and Wales, USA, Australia, Scotland, Canada, New Zealand, and Germany were analysed.
\end{abstract}

Methods - Crude annual mortality rates were calculated and rates standardised by Poisson regression to allow assessment of changes over time and comparison between countries, sexes, and age groups. The relative trends in mortality from CFA and PIF were assessed by calculating the annual ratio of CFA to PIF deaths.

Results - Men were more likely than women to die from both CFA and PIF in all countries. The highest standardised CFA mortality rate occurred in England and Wales, and the lowest in Germany. Since 1979 mortality from CFA has increased in England and Wales, Australia, Scotland and Canada, but there was no trend in CFA mortality in New Zealand or Germany. In the USA mortality from CFA was low and has fallen. Mortality from PIF increased in all countries except New Zealand and Germany, and the highest PIF mortality, together with the greatest increase over time, was seen in the USA. Changes over time in the annual ratio of CFA to PIF deaths in all countries were small, implying that diagnostic transfer is not a major cause of the increasing CFA mortality.

Conclusions - Mortality from CFA continues to increase in England and Wales and in many other countries. Diagnostic transfer from PIF does not appear to be a major cause of this.

(Thorax 1996;51:711-716)

Keywords: cryptogenic fibrosing alveolitis, post inflammatory fibrosis, mortality, epidemiology.

Cryptogenic fibrosing alveolitis (CFA) is an interstitial lung disease which, though first recognised in $1935,{ }^{1}$ did not receive a specific
International Classification of Diseases (ICD) code until the ninth ICD revision in $1979 .^{2}$ Until 1979 deaths from CFA were included in broader code categories with other diseases such as chronic interstitial pneumonia. In an analysis of CFA mortality data for England and Wales since 1979 we have previously shown that mortality from CFA increased approximately twofold between 1979 and 1988, but that over $40 \%$ of deaths coded as post inflammatory fibrosis (PIF) were also likely to be due to CFA. ${ }^{3}$ It is therefore not clear whether the increase in registered CFA mortality in England and Wales is the result of diagnostic transfer from PIF.

In the present study our objectives were to determine whether mortality from CFA is still increasing in England and Wales, and to establish whether CFA mortality has also increased significantly over time in other countries. We have also inspected the relative trends in CFA and PIF mortality to determine whether these are consistent with a true rise in mortality from these diseases or are more suggestive of diagnostic transfer from PIF to CFA. Mortality rates from CFA and PIF were compared between sexes, countries, and age groups using reported annual mortality data for CFA and PIF in England and Wales, Australia, Canada, Scotland, Germany, USA, and New Zealand.

\section{Methods}

DATA COLLECTION

Annual mortality figures for CFA (ICD code 516.3) and PIF (ICD code 515), together with annual total population estimates, both subdivided by age and sex, were collected for England and Wales, Scotland, Australia, Canada, New Zealand, Germany, and USA for as many years for which data were available since 1979. Data for England and Wales were obtained from the annual mortality statistics published by the Office of Population Censuses and Surveys (OPCS). ${ }^{4}$ Data for Scotland, Australia, Canada, New Zealand, and Germany were obtained by direct application to the OPCS equivalent for each country, and data for the USA were downloaded from the Centre for Disease Control computer database.

COMPARISON OF CFA AND PIF MORTALITY DATA BETWEEN COUNTRIES, SEXES, AND AGE GROUPS To compare the rates of mortality between sexes, age groups, and countries the number of deaths in each subgroup, together with the relevant denominator populations, were summed for the years that data were available 
Table 1 Sex and country specific mortality rates for CFA for data pooled over time

\begin{tabular}{|c|c|c|c|c|c|c|}
\hline \multirow[t]{2}{*}{ Country } & \multicolumn{3}{|c|}{ Men compared with women } & \multicolumn{3}{|c|}{ Countries compared with England and Wales } \\
\hline & Rate ratio & $95 \% C I$ & $p$ value & Rate ratio & $95 \% C I$ & $p$ value \\
\hline England and Wales & $2 \cdot 326$ & 2.225 to 2.432 & $<0.001$ & 1.000 & & \\
\hline Scotland & 1.829 & 1.566 to 2.136 & $<0.001$ & $0 \cdot 891$ & 0.823 to 0.965 & $<0.005$ \\
\hline Canada & 1.887 & 1.620 to 2.197 & $<0.001$ & $0 \cdot 269$ & 0.249 to 0.291 & $<0.001$ \\
\hline Australia & 1.993 & 1.738 to $2 \cdot 287$ & $<0.001$ & 0.495 & 0.462 to 0.531 & $<0.001$ \\
\hline New Zealand & 1.965 & 1.403 to 2.751 & $<0.001$ & 0.672 & 0.569 to 0.792 & $<0.001$ \\
\hline Germany & 1.571 & 1.000 to 2.468 & 0.050 & 0.017 & 0.014 to 0.022 & $<0.001$ \\
\hline USA & 1.806 & 1.648 to 1.979 & $<0.001$ & 0.087 & 0.083 to 0.092 & $<0.001$ \\
\hline
\end{tabular}

and standardised using Poisson regression modelling with the EGRET statistical package. ${ }^{5}$ In view of the small numbers of deaths in those aged under 44 years, age ranges were grouped together as $0-44,45-54,55-64,65-74,75-84$, and $>85$ years.

\section{TIME TRENDS IN CFA AND PIF MORTALITY}

Crude annual mortality rates per 100000 population were calculated for both CFA and PIF using the total numbers of deaths from each disease as the numerator and the total estimated population as the denominator. Annual mortality rates were then standardised with adjustment for age and sex using Poisson regression modelling. Trends in mortality were assessed for each country for the population as a whole, and within specific age groups. Since minor changes to the rules regarding coding were implemented in England and Wales in $1983,{ }^{6}$ the analysis was repeated using data for the years from 1984 onwards only. To assess the relative trends in mortality from PIF and CFA over time the annual ratios of CFA to PIF deaths were calculated for each country and analysed by linear regression.

\section{Results}

Data were available for CFA and PIF deaths in Scotland, Australia, and Canada from 1979 to 1991, in England and Wales from 1979 to

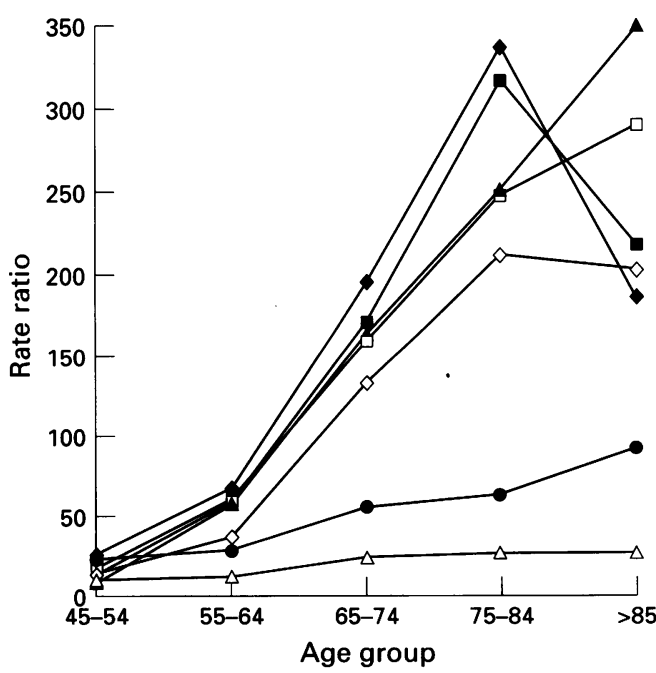

Figure 1 Rate ratios of age group-specific mortality from cryptogenic fibrosing alveolitis (CFA) compared with mortality in the 0-44 year age group pooled over available time period in England and Wales ( $)$, Scotland ( $\square$ ), Canada $(\diamond)$, Australia $(\diamond)$, New Zealand (४), Germany ( $\triangle$ ), and the USA (O).
1992, in the USA from 1979 to 1988 , in New Zealand from 1980 to 1987 , and in Germany from 1987 to 1992 .

SEX, AGE GROUP, AND COUNTRY SPECIFIC MORTALITY RATES FOR CFA FOR DATA POOLED OVER TIME

After adjustment for age, men were significantly more likely to die from CFA than women in all countries (table 1) and, with adjustment for sex, mortality from CFA appeared to increase with age in all countries except Germany (fig 1 ). With adjustment for age and sex there were significant differences in CFA mortality rates between countries, with England and Wales having the highest rate, followed by Scotland, New Zealand, Australia and Canada, whilst CFA mortality rates in Germany and the USA were an order of magnitude lower (table 1). Since data were available for only a limited number of years for New Zealand and Germany, the comparison was repeated using only data from the years in common with England and Wales, but results were similar (Germany odds ratio (OR) compared with England and Wales $0.014,95 \%$ confidence interval (CI) 0.011 to $0.018, p<0.001$, New Zealand OR $0 \cdot 776,95 \%$ CI 0.648 to $0.905, \mathrm{p}<0.001$ ).

TIME TRENDS IN COUNTRY AND AGE GROUP SPECIFIC MORTALITY RATES FROM CFA The crude CFA mortality rates suggested that mortality from CFA has increased in England

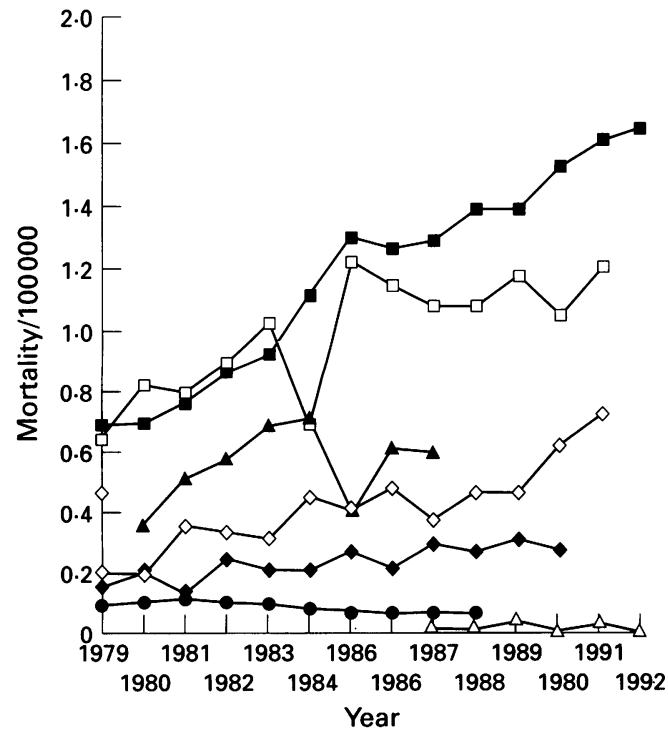

Figure 2 Crude mortality rates for cryptogenic fibrosing alveolitis (CFA) in England and Wales ( ), Scotland $(\square)$, Canada $(\diamond)$, Australia $(\diamond)$, New Zealand (४), Germany ( $\triangle$, and the USA ( 
Table 2 Rate ratios for annual increase in CFA mortality

\begin{tabular}{|c|c|c|c|c|c|c|c|c|c|}
\hline \multirow[t]{2}{*}{ Country } & \multicolumn{3}{|c|}{ Within each country adjusted for age and sex } & \multicolumn{6}{|c|}{ Within each age group adjusted for sex } \\
\hline & Rate ratio & $95 \% C I$ & $p$ value & $0-44$ & $45-54$ & $55-64$ & $65-74$ & $75-84$ & $>85$ \\
\hline England and Wales & 1.065 & 1.059 to 1.071 & $<0.001$ & $1 \cdot 018$ & 1.023 & $1 \cdot 054^{*}$ & $1 \cdot 066^{*}$ & $1 \cdot 070^{*}$ & $1 \cdot 098^{*}$ \\
\hline Scotland & 1.035 & 1.014 to 1.057 & $<0.001$ & 1.003 & $1 \cdot 002$ & $1 \cdot 043$ & $1 \cdot 049^{* *}$ & 1.031 & 0.997 \\
\hline Canada & 1.045 & 1.022 to 1.068 & $<0.001$ & $1 \cdot 105$ & 1.073 & 1.032 & 1.006 & $1.099^{*}$ & $1 \cdot 022$ \\
\hline Australia & 1.077 & 1.057 to 1.098 & $<0.001$ & 1.078 & $1 \cdot 061$ & $1 \cdot 020$ & $1.065^{*}$ & $1 \cdot 115^{*}$ & $1 \cdot 161^{*}$ \\
\hline New Zealand & 1.028 & 0.956 to $1 \cdot 104$ & NS & $1 \cdot 213$ & $0 \cdot 728$ & 1.090 & $1 \cdot 015$ & 1.039 & 0.974 \\
\hline Germany & 1.037 & 0.910 to $1 \cdot 181$ & NS & 0.915 & 0.971 & $1 \cdot 077$ & 0.984 & $1 \cdot 278$ & $0 \cdot 868$ \\
\hline USA & 0.953 & 0.938 to 0.968 & $<0.001$ & $0 \cdot 893^{*}$ & $0.941^{* * *}$ & $0.921^{*}$ & $0.960^{* *}$ & $0.971 * * *$ & $1 \cdot 014$ \\
\hline
\end{tabular}

${ }^{*} \mathrm{p}<0.001 ;{ }^{* *} \mathrm{p}<0.005 ; * * * \mathrm{p}<0.05$.

Table 3 Sex and country specific mortality rates for PIF for data pooled over time

\begin{tabular}{|c|c|c|c|c|c|c|}
\hline \multirow[b]{2}{*}{ Country } & \multicolumn{3}{|c|}{ Men compared with women } & \multicolumn{3}{|c|}{ Countries compared with England and Wales } \\
\hline & Rate ratio & $95 \% C I$ & $p$ value & Rate ratio & $95 \% C I$ & $p$ value \\
\hline England and Wales & $2 \cdot 246$ & $2 \cdot 139$ to $2 \cdot 358$ & $<0.001$ & 1.000 & & \\
\hline Scotland & $1 \cdot 728$ & 1.512 to 1.975 & $<0.001$ & 1.456 & 1.358 to 1.562 & $<0.001$ \\
\hline Canada & $1 \cdot 851$ & 1.745 to 1.964 & $<0.001$ & 1.971 & 1.898 to 2.046 & $<0.001$ \\
\hline Australia & $2 \cdot 215$ & $2 \cdot 016$ to $2 \cdot 434$ & $<0.001$ & $1 \cdot 317$ & 1.251 to 1.386 & $<0.001$ \\
\hline New Zealand & $2 \cdot 403$ & 1.662 to 3.476 & $<0.001$ & 0.715 & 0.599 to 0.855 & $<0.005$ \\
\hline Germany & $1 \cdot 841$ & 1.740 to 1.946 & $<0.001$ & $1 \cdot 337$ & 1.289 to 1.386 & $<0.001$ \\
\hline USA & $1 \cdot 754$ & $1 \cdot 717$ to $1 \cdot 791$ & $<0.001$ & 1.978 & 1.928 to 2.030 & $<0.001$ \\
\hline
\end{tabular}

and Wales, Scotland, Australia, and Canada since 1979 (fig 2), although a temporary decrease was seen in Scotland in 1984. These increases were statistically significant after adjustment for age and sex (table 2), and when the analysis was repeated for England and Wales using data only from 1984 onwards the increase remained significant (OR for each year $1.038,95 \%$ CI 1.029 to $1.048, \mathrm{p}<0.001)$. In New Zealand and Germany there was no significant trend in CFA mortality and in the USA there was a significant decrease in mortality over time. Within each age group significant increases in mortality over time were confined to those aged over 65 except for England and Wales, and in three countries there were either no age specific increases in mortality over time (New Zealand and Germany) or mortality was significantly decreased (USA) (table 2).

SEX, AGE GROUP AND COUNTRY SPECIFIC MORTALITY RATES FOR PIF FOR DATA POOLED OVER TIME

Analysis of PIF data revealed that in all countries, after adjustment for age, men were significantly more likely to die from PIF than women (table 3) and, following adjustment for sex, mortality from PIF increased with age (fig 3). With adjustment for age and sex there were significant differences in PIF mortality rates between countries, with the highest rates occurring in the USA and Canada and the lowest rates in England and Wales and New Zealand (table 3). The repeat analysis for New Zealand and Germany using only data from the years in common with England and Wales gave similar results (Germany OR $1 \cdot 230,95 \%$ CI $1 \cdot 178$ to $1 \cdot 285, \mathrm{p}<0.001$, New Zealand OR 0.738, 95\% CI 0.616 to $0.883, \mathrm{p}<0.001$ ).

TIME TRENDS IN COUNTRY AND AGE GROUP SPECIFIC MORTALITY RATES FROM PIF Crude mortality rates for PIF have increased since 1979 in all countries except New Zealand and Germany (fig 4), although a temporary decrease was seen in Scotland in 1987. Following adjustment for age and sex, these increases were significant in all countries except New Zealand and Germany (table 4). Within each age group significant increases in PIF mortality over time were present, predominantly in the $45-54,65-74$, and $75-84$ age groups, except for New Zealand where there were no significant increases in PIF mortality over time in any age group (table 4 ).

RATIO OF ANNUAL MORTALITY FROM CFA TO PIF The annual changes in the ratios of CFA to PIF deaths were small, although for England and Wales and Australia the ratio did increase, and for the USA it decreased significantly over time (table 5).

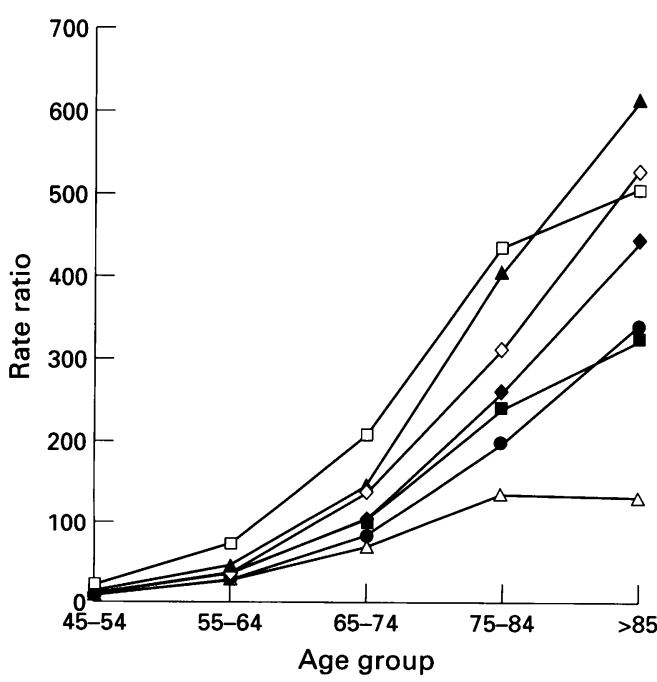

Figure 3 Rate ratios of age group-specific mortality from post inflammatory fibrosis (PIF) compared with mortality in the 0-44 age group pooled over available time period in England and Wales ( $\mathbf{D}$, Scotland ( $\square$ ), Canada $(\diamond)$,

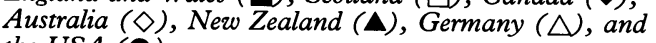
the USA (O). 
Table 4 Rate ratios for annual change in PIF mortality

\begin{tabular}{|c|c|c|c|c|c|c|c|c|c|}
\hline \multirow[t]{2}{*}{ Country } & \multicolumn{3}{|c|}{ Within each country adjusted for age and sex } & \multicolumn{6}{|c|}{ Within each age group adjusted for sex } \\
\hline & Rate ratio & $95 \% C I$ & $p$ value & $0-44$ & $45-54$ & $55-64$ & $65-74$ & $75-84$ & $>85$ \\
\hline England and Wales & $1 \cdot 027$ & 1.021 to 1.033 & $<0.001$ & $0.989^{*}$ & $1 \cdot 350^{* * *}$ & $1 \cdot 001$ & $2 \cdot 237^{*}$ & $1.038^{*}$ & $1 \cdot 060$ \\
\hline Scotland & $1 \cdot 030$ & 1.012 to 1.049 & $<0.001$ & 0.861 & $1 \cdot 169$ & 0.981 & 1.028 & $1.065^{*}$ & $1 \cdot 064^{* * *}$ \\
\hline Canada & $1 \cdot 027$ & 1.019 to 1.036 & $<0.001$ & 1.040 & $1.684^{*}$ & 1.003 & $1.032^{*}$ & $1.031 \%$ & $1 \cdot 040^{*}$ \\
\hline Australia & 1.026 & 1.013 to 1.038 & $<0.001$ & $0.910^{* * *}$ & $1 \cdot 803^{* * *}$ & 1.018 & $1 \cdot 022^{* * *}$ & $1 \cdot 047^{*}$ & 1.019 \\
\hline New Zealand & $1 \cdot 014$ & 0.938 to 1.095 & NS & $1 \cdot 171$ & 0.642 & $1 \cdot 025$ & $1 \cdot 046$ & 0.938 & $1 \cdot 230$ \\
\hline Germany & $1 \cdot 011$ & 0.995 to 1.028 & NS & 1.029 & $1.448^{*}$ & 0.972 & 1.012 & $1 \cdot 041^{* *}$ & 1.040 \\
\hline USA & 1.039 & 1.036 to 1.043 & $<0.001$ & 1.009 & $1 \cdot 383^{*}$ & $1.023^{*}$ & $1.038^{*}$ & $1 \cdot 046^{*}$ & $1.058^{*}$ \\
\hline
\end{tabular}

${ }^{*} \mathrm{p}<0.001 ;{ }^{* *} \mathrm{p}<0.005 ;{ }^{* * *} \mathrm{p}<0.05$.

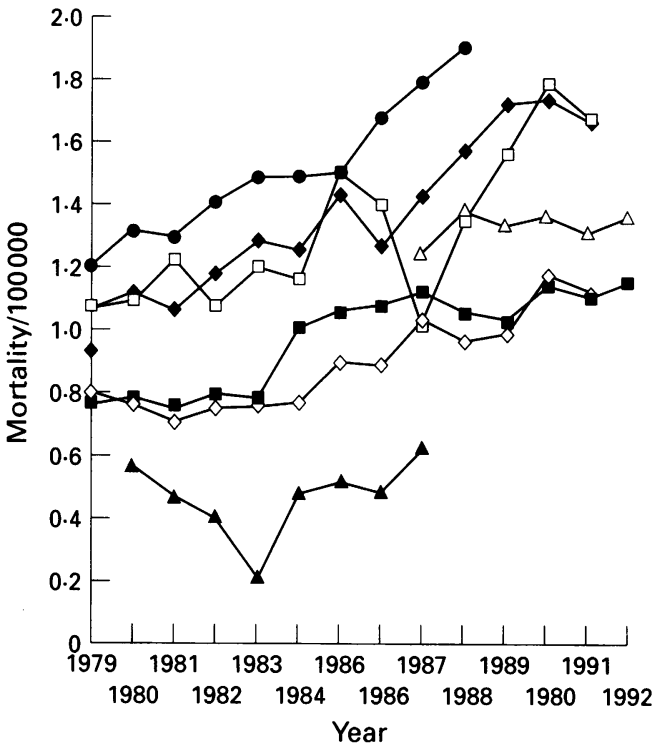

Figure 4 Crude mortality rates for post inflammatory fibrosis (PIF) in England and Wales (D), Scotland ( $\square$ ),

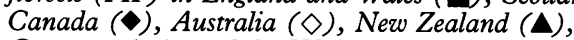
Germany ( $\triangle$, and the USA (O).

Table 5 Linear regression of the annual ratios of CFA to PIF mortality

\begin{tabular}{lccc}
\hline Country & $\begin{array}{l}\text { Annual } \\
\text { change } \\
\text { in ratio }\end{array}$ & $\begin{array}{l}\text { 95\% confidence } \\
\text { interval }\end{array}$ & p value \\
\hline England and Wales & 0.042 & 0.034 to 0.049 & $<0.0001$ \\
Scotland & 0.006 & -0.014 to 0.026 & NS \\
Canada & 0.003 & -0.001 to 0.007 & NS \\
Australia & 0.020 & 0.007 to 0.034 & 0.01 \\
New Zealand & -0.003 & -0.261 to 0.255 & NS \\
Germany & 0.0005 & -0.005 to 0.004 & NS \\
USA & -0.005 & -0.003 to -0.006 & 0.0005 \\
\hline
\end{tabular}

\section{Discussion}

This study shows that the increase in registered CFA mortality in England and Wales from 1979 to 1988 noted previously ${ }^{3}$ has continued, and that similar increases have occurred in Scotland, Australia, and Canada during the period since 1979 for which data were available for these countries. Overall, the highest mortality rates for CFA were seen in England and Wales, followed by Scotland, New Zealand, Australia, and Canada. The CFA mortality rates for the USA and Germany were considerably lower than those for the other countries, and the USA data were exceptional in demonstrating a significant fall in CFA mortality over time. Temporary decreases in reported CFA mortality were noted in Scotland in 1984 and in New Zealand in 1985, and in PIF mortality in Scotland in 1987; the reasons for this are not clear. In all countries men were significantly more likely to die from CFA than women, and there was a trend towards increasing mortality from CFA with increasing age. For all countries except the USA and Germany the trends in PIF mortality were similar to those for CFA mortality, and significant increases over time were seen in PIF mortality in England and Wales, Scotland, Canada, and Australia. In contrast to CFA, PIF mortality rates in the USA and Germany were of a similar magnitude to those for other countries and, in the USA, PIF mortality increased significantly over time. The patterns of PIF mortality rates for the different ages and sexes were similar to those for CFA with men more likely to die from PIF than women and mortality increasing with age but, in contrast to CFA, PIF mortality was also increasing over time in the 45-54 year age group.

Although the increases seen in the number of registered deaths from CFA may reflect a true increase in mortality, they could also be the result of changes in diagnostic labelling either by the physician assigning the cause of death for a patient or during subsequent coding of the cause given on the death certificate. The accuracy of death certificate coding has been investigated for England and Wales and the specificity of CFA mortality coding found to be high at $83 \% .{ }^{3}$ However, a substantial proportion of deaths $(45 \%)$ coded as PIF were also found to meet diagnostic criteria for CFA. Thus it is possible that decreasing use of the less specific PIF code over time, with an increase in the use of the specific code for CFA, may explain the rises seen in CFA mortality rates. If such diagnostic transfer were an important factor then PIF mortality should have fallen over time, or at least the ratio of CFA to PIF mortality should have increased. However, in the four countries in which an increase in CFA mortality occurred, simultaneous increases were seen in PIF mortality and annual changes in the ratio of CFA to PIF deaths were small. Thus, it appears unlikely that diagnostic transfer was a major contributor to the increase in CFA mortality in these countries.

Changes to the actual practice of coding may also influence reported mortality. In 1984 the rules in England and Wales were altered to come into line with the recommendations of the World Health Organisation, such that in cases in which an unspecified pneumonia was recorded in the first part of the death certificate the underlying cause of death was coded according to the diagnosis given in the second part. To assess the effects of this change dual 
coding using both sets of rules was used in $1984^{6}$ and, as might be expected, the number of deaths reported as being from CFA was increased under the new rules. The amount of this increase was $6 \%$, and this effect can be seen in the plot of crude mortality from CFA as an upward step in 1984. However, although this change may explain some of the increase in CFA mortality seen in England and Wales in 1984 , it cannot explain the progressive increase seen both before and after this time. Furthermore, when data for the years before 1984 were excluded and the analysis repeated, the significant trend remained.

Changes in clinical practice leading to an increased recognition of fibrotic lung diseases may also produce changes in registered mortality rates from CFA. It is likely that more detailed investigation of patients during the 1980 s and 1990s, particularly amongst the elderly, has contributed to an increase in ascertainment of CFA mortality. Ultimately, however, the effect of increased diagnostic ascertainment on reported mortality should diminish with time as the registered rate approaches the true one, and to date this does not appear to have occurred in any of the four countries where CFA mortality is currently increasing. From this it follows that, if increased case ascertainment is responsible for the increases in registered CFA mortality, then a substantial proportion of CFA deaths still remain undiagnosed, or at least unregistered as such.

Another explanation for the trends in CFA and PIF mortality is that they reflect a true increase in mortality from CFA in England and Wales, Scotland, Canada, and Australia. What might explain, however, the different trends in CFA mortality seen in the USA, Germany, and New Zealand? The CFA mortality rates for the USA are particularly unusual since they are low relative to other countries and are falling significantly over time. If the USA had the same mortality rate from CFA as England and Wales then the expected number of deaths would be approximately 2500 when, in fact, the average number of deaths reported each year from CFA is currently less than 200 . This suggests that either the disease is far less common in the USA than in England and Wales or that there are marked differences in the diagnosis or coding of CFA deaths in the USA. The best estimate of CFA prevalence in England and Wales is six per $100000^{7}$ based on a case control study in Nottingham, whilst that for the USA is 20 per 100000 derived from a population based registry in New Mexico. ${ }^{8}$ Although different methods were used to produce these figures, they certainly do not suggest that the disease is less common in the USA. Assuming patients with CFA to have a mean survival time of five years, ${ }^{9}$ these estimates of CFA prevalence suggest that the incidence (and therefore the approximate death rate) of CFA in the USA should be in the range of 1-4 per 100000 per year, and thus an estimated 2500-10000 people with CFA will die each year in the USA. The simplest explanation for the difference between the observed number of deaths of 200 and the expected number of between 2500 and 10000 is that deaths from CFA in the USA are systematically coded as PIF and this, in turn, explains why the PIF mortality rates are so high. Evidence to support this hypothesis is provided by the investigation of the 51 cases of CFA from the New Mexico Interstitial Lung Disease Registry who died during follow up (personal communication, Dr D Coultas). For these cases PIF was recorded on the death certificates of $39 \%$ and CFA in only $22 \%$. Examination of the vital statistics for these cases revealed that none had been coded as dying from CFA, but that $33 \%$ were coded as dying from PIF. The data for Germany show similar trends to those from the USA and, although the expected number of deaths each year is $800-3200$, the average number of reported deaths is less than 20 and here also systematic miscoding of CFA as PIF may be occurring. In New Zealand the CFA mortality rates are similar to those in England and Wales and PIF mortality rates are lower. Here, the absence of any clear trend in CFA mortality may be partly explained by the fact that data were only available for a limited number of years.

In all countries men were significantly more likely to die from CFA than women, and in all except Germany there was a trend towards increased mortality with age. These findings are consistent with those from clinical case series $^{10-14}$ and the New Mexico Interstitial Lung Disease Registry ${ }^{8}$ and, although the reason for the gender difference is unknown, they raise the possibility that traditionally male occupational exposures may be risk factors for the disease. Two case control studies, together with a series of case reports, have suggested that exposure to metal dust and wood dust may be associated with CFA. ${ }^{715-19}$

In conclusion, this study has shown that mortality from CFA has increased significantly in several countries since 1979 and that this trend does not appear to be due to diagnostic transfer from PIF. In the USA, however, mortality rates from CFA were low and have fallen significantly over time, and this may reflect systematic coding of CFA as PIF. The increasing importance of CFA as a cause of death and disability, together with the poor response of CFA to treatment, ${ }^{2021}$ mean that it is important that the potential cause (or causes) of this disease are recognised so that steps may be taken where possible to prevent it.

1 Hamman L, Rich AR. Fulminating diffuse interstitial fibrosis of the lungs. Trans Am Clin Climatol Assoc 1935;51:154-63. 2 World Health Organisation. International Classification of Diseases 1975. 9th revision. 9th ed. Geneva: WHO, 1977.

3 Johnston I, Britton J, Kinnear W, Logan R. Rising mortality

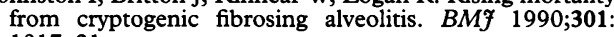
from cryptor

4 Office of Population Censuses and Surveys. Mortality statistics 1979-92. London: HMSO, 1980-93 (Series DH2).

5 Anonymous. EGRET reference manual. Seattle: Statistics and Anonymous. EGRET reference manual. Seattle: Statistics and
Epidemiology Research Corporation and Cytel Software Corporation, 1990

6 Office of Population Censuses and Surveys. Mortality statistics 1984. London: HMSO, 1985 (Series DH2).

7 Scott J, Johnston I, Britton J. What causes cryptogenic fibrosing alveolitis? A case-control study of environmental exposure to dust. BMF 1990;301:1015-7.

8 Coultas DB, Zumwalt RE, Black WC, Sobonya RE. The epidemiology of interstitial lung diseases. Am $\mathcal{Y}$ Respir Crit Care Med 1994;150:967-72. 
9 Turner-Warwick M, Burrows B, Johnson A. Cryptogenic fibrosing alveolitis: response to corticosteroid treatment fibrosing alveolitis: response to corticosteroid tr.

10 Turner-Warwick M, Burrows B, Johnson A. Cryptogenic fibrosing alveolitis: clinical features and their influence on fibrosing alveolitis: clinical features
survival. Thorax 1980;35:171-80.

11 Carrington CB, Gaensler EA, Coutu RE, Fitzgerald MX, Gupta RG. Natural history and treated course of usual and desquamative interstitial pneumonia. $N$ Engl $7 \mathrm{Med}$ 1978;298:801-8.

12 Wright $\mathrm{PH}$, Heard BE, Steel SJ, Turner-Warwick Cryptogenic fibrosing alveolitis: assessment by graded Cryptogenic fibros trephine lung biopsy histology compared with clinical, radiographic and physiological features. Br f Dis Chest
1981;75:61-70.

13 Wells AU, Cullinan P, Hansell DM, Rubens MB, Black $\mathrm{CM}$, Newman-Taylor AJ, et al. Fibrosing alveolitis associated with systemic sclerosis has a better prognosis than lone cryptogenic fibrosing alveolitis. Am $\mathcal{F}$ Respir Crit Care Med 1994;149:1583-90.

14 Agusti C, Xaubet A, Augusti AGN, Roca J, Ramirez J, Rodriguez-Roisin R. Clinical and functional assessment of patients with idiopathic pulmonary fibrosis: results of a three year follow up. Eur Respir f 1994;7:643-50.

15 Iwai K, Mori T, Yamada N, Yamaguchi M, Hosoda Y.
Idiopathic pulmonary fibrosis: epidemiological approaches to occupational exposure. Am 7 Respir Crit Care Med 1994; 150:670-5.

16 Nemery B, Nagels J, Verbeken E, Dinsdale D, Demedts M Rapidly fatal progression of cobalt lung in a diamond polisher. Am Rev Respir Dis 1990;141:1373-8.

17 Vallyathan V, Bergeron WN, Robichaux PA, Craighead JE Pulmonary fibrosis in an aluminium arc welder. Chest 1982;81:372-4.

18 De Vuyst P, Dumortier P, Rickaert F, Van De Weyer R, Lenclud C, Yernaukt J. Occupational lung fibrosis in an aluminium polisher. Eur f Respir Dis 1986;68:131-40.

19 Ramage JE, Jr., Roggli VL, Bell DY, Piantadosi CC. Interstitial lung disease and domestic wood burning. Am Rev Respir Dis 1988;137:1229-32.

20 Raghu G, Depaso WJ, Cain K, Hammar SP, Wetzel CE, Dreis DF, et al. Azathioprine combined with prednisone in the treatment of idiopathic pulmonary fibrosis: a prospective double-blind, randomized, placebo-controlled clinical trial. Am Rev Respir Dis 1991;144:219-6.

21 Johnson MA, Kwan S, Snell NJ, Nunn AJ, Darbyshire JH, Turner-Warwick M. Randomised controlled trial comparing prednisolone alone with cyclophosphamide and low dose prednisolone in combination in cryptogenic fibrosing alveolitis. Thorax 1989;44:280-8. 